\title{
Early Insights from Statistical and Mathematical Modeling of Key Epidemiologic Parameters of COVID-19
}

Matthew Biggerstaff, Benjamin J. Cowling, Zulma M. Cucunubá, Linh Dinh, Neil M. Ferguson, Huizhi Gao, Verity Hill, Natsuko Imai, Michael A. Johansson, Sarah Kada, Oliver Morgan, Ana Pastore y Piontti, Jonathan A. Polonsky, Pragati Venkata Prasad, Talia M. Quandelacy, Andrew Rambaut, Jordan W. Tappero, Katelijn A. Vandemaele, Alessandro Vespignani, K. Lane Warmbrod, Jessica Y. Wong, for the WHO COVID-19 Modelling Parameters Group ${ }^{1}$

We report key epidemiologic parameter estimates for coronavirus disease identified in peer-reviewed publications, preprint articles, and online reports. Range estimates for incubation period were 1.8-6.9 days, serial interval $4.0-7.5$ days, and doubling time $2.3-7.4$ days. The effective reproductive number varied widely, with reductions attributable to interventions. Case burden and infection fatality ratios increased with patient age. Implementation of combined interventions could reduce cases and delay epidemic peak up to 1 month. These parameters for transmission, disease severity, and intervention effectiveness are critical for guiding policy decisions. Estimates will likely change as new information becomes available.

n December 31, 2019, authorities in China notified the World Health Organization (WHO) of a pneumonia cluster of unknown etiology in Wuhan (1); a novel coronavirus was subsequently isolated. As of March 7, 2020, coronavirus disease (COVID-19) and its causative agent, severe acute respiratory syndrome coronavirus 2 (SARS-CoV-2), had resulted in 101,927 cases and 3,486 deaths in 94

Author affiliations: Centers for Disease Control and Prevention, Atlanta, Georgia, USA (M. Biggerstaff, M.A. Johansson, S. Kada, P.V. Prasad, T.M. Quandelacy); University of Hong Kong, Hong Kong, China (B.J. Cowling, H. Gao, J.Y. Wong); Imperial College London, London, UK (Z.M. Cucunubá, N.M. Ferguson, N. Imai); World Health Organization, Geneva, Switzerland (L. Dinh, O. Morgan, J.A. Polonsky, J.W. Tappero, K.A. Vandemaele, K.L. Warmbrod); University of Edinburgh, Edinburgh, Scotland, UK (V. Hill, A. Rambaut); Northeastern University, Boston, Massachusetts, USA (A. Pastore y Piontti, A. Vespignani); ISI Foundation, Turin, Italy (A. Vespignani) countries spanning 6 continents (2). The spectrum of illness ranged from asymptomatic infection to mild disease (e.g., fever, dry cough, and myalgias), pneumonia, and death. Roughly $20 \%$ of cases require hospitalization for shortness of breath; death is associated with increasing age and underlying conditions (e.g., hypertension, cardiovascular disease, and diabetes) (3).

We review major parameters of COVID-19 transmission dynamics from statistical and mathematical modeling studies using epidemiologic data reported in the first 60 days of the epidemic. We estimate the key components that contribute to future modeling on the effects of nonpharmaceutical interventions (NPIs) and to inform critical resource allocation decisions (4). Data estimates were current as of March 6,2020 , a few days before WHO characterized COVID-19 as a pandemic on March 11, 2020 (WHO Director General remarks, https://www.youtube. $\mathrm{com} /$ watch? $\mathrm{v}=\mathrm{sbT6AANFOm} 4)$, and were subject to change as more information becomes available.

\section{Methods and Results}

We reviewed the literature on key epidemiologic parameters (Table 1) relating to the COVID-19 epidemic. This report is not a formal systematic review because the epidemic is rapidly unfolding and useful data sources exist that have not yet been peer reviewed. We searched the peer-reviewed and gray literature, including preprints, research reports, and forum posts. We conducted searches for individual parameters during February 25-March 6, 2020, on PubMed, medRxiv, bioRxiv, arXiv, SSRN, Research 
Table 1. Key parameters and definitions for modeling of coronavirus disease

\begin{tabular}{ll}
\hline Parameter & Definition \\
\hline Basic reproduction number $\left(R_{0}\right)$ & Average number of persons infected by a single infected individual in a fully susceptible population \\
\hline Time-varying or effective & $\begin{array}{l}\text { Average number of persons infected by an infected individual in a population in the context of } \\
\text { reproduction number }\left(R, R_{t}, R_{E}\right)\end{array}$ \\
\hline changing transmission patterns, such as those resulting from interventions and acquired immunity \\
\hline Serial interval & $\begin{array}{l}\text { Time between infection and symptom onset } \\
\text { cases }\end{array}$ \\
\hline Generation interval & Average time between infection of a primary case and infection of linked secondary cases \\
\hline Doubling time & Average time for the daily case count to double \\
\hline Infectious period & Period during which an infected host, with or without symptoms, can transmit an infectious agent to \\
& susceptible persons, directly or indirectly \\
\hline Case-fatality ratio & Proportion of cases that result in death (with case defined in numerous ways) \\
\hline Infection-fatality ratio & Proportion of all infections (confirmed, symptomatic, asymptomatic) that result in death \\
\hline Mean evolutionary rate & Average rate at which mutations accumulate per base pair in the genome over the course of a year \\
\hline
\end{tabular}

Square, Virological, Imperial College COVID reports, and Wellcome Open Research. Search terms centered on the various names of the disease and virus over the course of the epidemic ("nCoV," "COVID," "SARSCoV-2," "novel coronavirus") and keywords relating to each of the epidemiologic parameters or characteristics considered (Appendix Table 1, https:// wwwnc.cdc.gov/EID/article/26/11/20-1074-App1. pdf). We selected genetic epidemiology estimates, such as evolutionary rate and time from last common ancestor, from Virological (http://virological.org). We included articles in English and Chinese if they used mathematical or statistical methods for adjustment of different biases and if they were either peer reviewed or non-peer reviewed requiring established methods (i.e., clarity about the data used, known statistical methods, and reported uncertainty) (5-8).

For each parameter, characteristics such as study population, assumptions, and analytical methods were summarized when patterns were discernible across estimates. Estimates were summarized as ranges to reflect remaining uncertainty. No metaanalyses were performed.

\section{$\mathbf{R}_{0}$ and $\mathbf{R}$}

One of the key early indicators of transmissibility of a novel pathogen is $R_{0^{\prime}}$ the basic reproduction number, which represents the average number of persons infected by an incident person in a fully susceptible population. Values for $R_{0}$ that are $>1$ are considered a critical threshold for epidemic growth. Mean $\mathrm{R}_{0}$ estimates for Hubei Province, China, ranged widely, 2.15.1 (peer-reviewed) and 2.0-7.7 (M.S. Majumder and K.D. Mandl, unpub. data, https://papers.ssrn.com/ sol3/papers.cfm?abstract_id=3524675; T. Liu et al., unpub. data, https://www.biorxiv.org/content/10.1101 /2020.01.25.919787v2; K. Mizumoto et al., unpub. data, https://www.medrxiv.org/content/10.1101/2020.02. 12.20022434v2.full.pdf; C. Zhou, unpub. data, https:/ / www.medrxiv.org/content/10.1101/2020.02.15.200 23440v2.full.pdf; H. Sun et al., unpub. data, https:/ / www.medrxiv.org/content/10.1101/2020.02.17.20024 257v1; J. Li et al., unpub. data, https:/ / www.medrxiv. org/content/10.1101/2020.02.18.20024315v1.full.pdf; S. Zhao et al, unpub. data, https://www.medrxiv. org/content/10.1101/2020.02.26.20028449v1.full.pdf; S. Zhao et al., unpub. data, https://doi.org/10.2139/ ssrn.3543150; Z. Zhuang et al., unpub. data, https:// www.medrxiv.org/content/10.1101/2020.03.02.200 30312v1.full.pdf; S. Zhao et al., unpub. data, https:/ / www.medrxiv.org/content/10.1101/2020.02.21.20026 $559 \mathrm{v} 1)$, reflecting a variety of assumptions and methods used and data uncertainty (9-17). A subset of more recent estimates accounted for the broad restrictions implemented on January 23 in Hubei explicitly and were lower than earlier estimates (1.0-2.9) $(\mathrm{H}$. Sun et al., unpub. data, https://www.medrxiv.org/content /10.1101/2020.02.17.20024257v1; L. Xu et al., unpub. data, https://www.medrxiv.org/content/10.1101/ 2020.02.25.20024398v1; L. Zhang et al., unpub. data, https://www.medrxiv.org/content/10.1101/2020.02. 16.20023804v1). Mean $\mathrm{R}_{0}$ estimates for provinces outside Hubei or for all of China were similar to those for Hubei before the implementation of travel restrictions (peer-reviewed range 0.4-3.9, preprint range: 0.6-6.4) (11,14,18-20; T. Liu et al., unpub. data, https://www. biorxiv.org/content/10.1101/2020.01.25.919787v2; H. Sun et al., unpub. data, https://www.medrxiv.org/ content/10.1101/2020.02.17.20024257v1; L. Xu et al., unpub. data, https://www.medrxiv.org/content/10. 1101/2020.02.25.20024398v1; L. Tindale et al., unpub. data, https://www.medrxiv.org/content/10.1101/ 2020.03.03.20029983v1; M. Shen et al., unpub. data, https://www.biorxiv.org/content/10.1101/2020.0 1.23.916726v1; L. Wang et al., unpub. data, https:/ / www.medrxiv.org/content/10.1101/2020.02.29.2002 9421v1.full.pdf; Ku et al., unpub. data, http://dx.doi. org/10.2139/ssrn.3543589). $R_{0}$ estimates for China and cases outside China attributed to exportation were generally lower (peer-reviewed range 2.1-3.2; preprint 
range 2.1 - 5.7) $(14,15,21$; J.M. Read et al., unpub. data, https://www.medrxiv.org/content/10.1101/2020.01. 23.20018549v2.full.pdf; C. Zhang and M.Wang, unpub. data, https://www.biorxiv.org/content/10.1101/202 0.01.25.919688v3; Q. Zhou et al., unpub. data, https:/ / www.medrxiv.org/content/10.1101/2020.02.06.20020 941v1.full.pdf; Volz et al., unpub. data, https:// spiral. imperial.ac.uk/bitstream/10044/1/77169/11/202002-15-COVID19-Report-5.pdf; Q. Zhao et al., unpub. data, https://www.medrxiv.org/content/10.1101/2 020.02.06.20020941v1), as were estimates for the Diamond Princess cruise ship (mean $R_{0} \approx 2.2$ ) (22; $S$. Zhao, unpub. data $\left[\mathrm{R}_{0}=2.1\right]$, https://doi.org/10.2139/ ssrn.3543150; S. Zhao, unpub. data $\left[\mathrm{R}_{0}=2.2\right]$, https:/ / www.medrxiv.org/content/10.1101/2020.02.26.20028 $449 v 1 . f u l l . p d f)$ and estimates for Singapore and South Korea (range 2.6-3.2; L. Tindale et al., unpub. data, https://www.medrxiv.org/content/10.1101/2020. 03.03.20029983v1; Z. Zhuang, unpub. data $\left[\mathrm{R}_{0}=2.6\right]$, https://www.medrxiv.org/content/10.1101/2020.03. 02.20030312v1.full.pdf) were generally lower. A metaanalysis of 7 early COVID-19 studies that accounted for uncertainty in assumptions estimated an $R_{0}$ of 2.9 (95\% CI 2.1-4.5; S.W. Park et al., unpub. data, https:/ / www.medrxiv.org/content/10.1101/2020.01.30.20019 877v4) (Figure 1).

High variability in $R_{0}$ estimates can result from a mix of data (e.g., time period of cases analyzed, data available by onset date), methods (e.g., $R_{0}$ as a component of early exponential growth, fitting case data to compartmental models), and assumptions (e.g., serial intervals, case ascertainment). In particular, serial interval estimates directly affect $R_{0}$ : shorter serial intervals suggest that fewer transmission events are required for rapid growth. However, most $R_{0}$ estimates reviewed here used serial intervals values between 7.5 (COVID-19) and 8.4 (SARS); these differences likely had limited effects $(7,9)$.

$\mathrm{R}_{0}$ reflects average transmission, not individuallevel transmission. Variability (dispersion) among individual-level contacts and transmission potential can lead to many persons infecting no others, whereas some infect many, as previously observed for severe acute respiratory syndrome (SARS) and Middle East respiratory syndrome (MERS) $(23,24)$. This pattern has also been observed for COVID-19, with estimates of the dispersion parameter <1 (e.g., 0.5 in Singapore [A. Tariq et al. unpub. data, https://www.medrxiv. org/content/10.1101/2020.02.21.20026435v4.full. pdf], 0.54 in China [14], 0.58 in Shenzhen [19]). These findings imply that a minority of cases may cause the majority of infections; for example, in Shenzhen, $8.9 \%$ of cases were found to cause $80 \%$ of infections (19).
Rigorous contact tracing data are needed to improve these estimates and identify opportunities to tailor interventions accordingly (25).

Explicit estimates of the time-varying or effective reproducton number, $R$ (often referred to as $R_{t}$ or $R_{E}$ ), can identify changes in transmission over time as a result of interventions and acquired immunity. Mean estimates of $\mathrm{R}$ before January 23 generally fall within the ranges of 2.3-2.6 (peer-reviewed $[26,27]$ ) and 3.9-6.2 (preprints; T. Liu et al., unpub. data, https://www.biorxiv.org/content/10.1101/2020.01 .25.919787v2; C. Wang et al., unpub. data, https:// www.medrxiv.org/content/10.1101/2020.03.03.2 0030593v1). Shortly after the travel restrictions, $R$ estimates ranging from $0.4-1.0$ (peer-reviewed) to 0.2-3.4 (preprints) indicated a decrease in transmission in Wuhan and other parts of China $(19,26$; $\mathrm{T}$. Liu et al., unpub data, https://www.biorxiv.org/

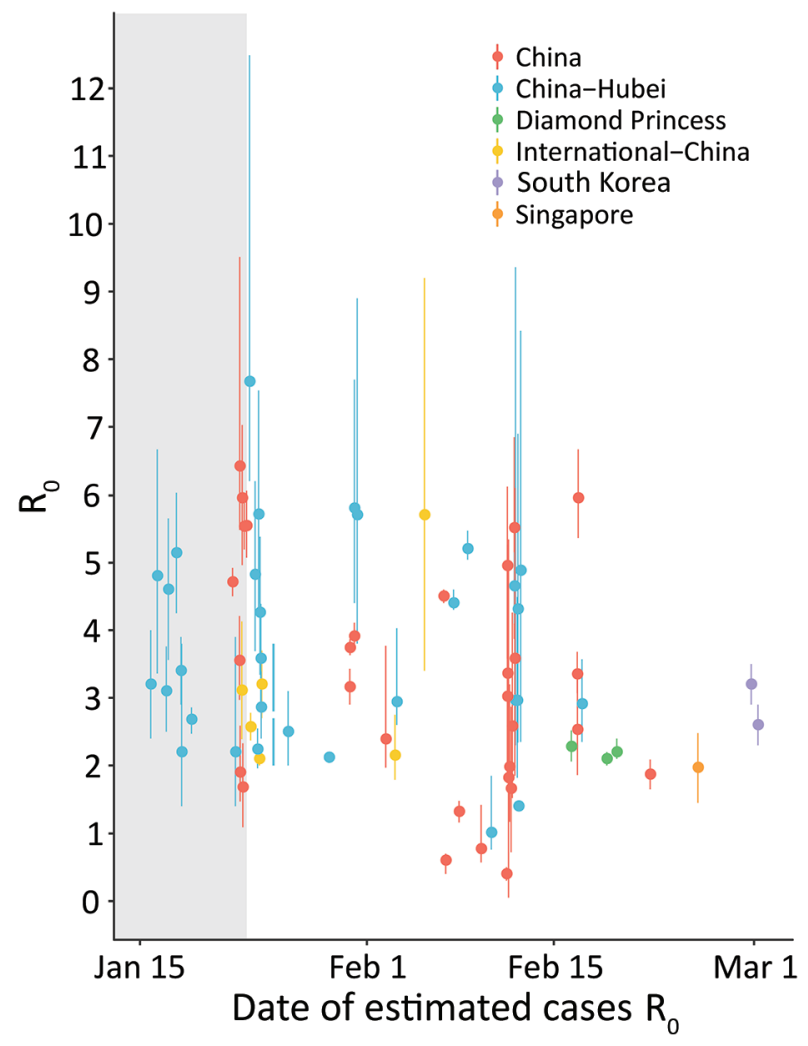

Figure 1. Basic reproduction number $\left(R_{0}\right)$ estimates for coronavirus disease by date of last reported cases analyzed and location. Points are mean or median estimates and error bars indicate $90 \%(12,13,15)$ or $95 \%$ bounds (i.e., confidence or credible intervals). International-China estimates are those using international cases or exported cases from China to infer $R_{0}$ in China or Hubei Province. Estimates for China refer to $R_{0}$ estimates at the national or province level, except for those exclusive estimating $\mathrm{R}_{0}$ for Hubei (China-Hubei). The gray shaded bar represents the time period before January 23, 2020, the date when broad restrictions were implemented in Hubei Province. 
content/10.1101/2020.01.25.919787v2; K. Mizumoto et al., unpub. data, https://www.medrxiv.org/cont ent/10.1101/2020.02.12.20022434v1.full.pdf; C. You et al., unpub. data, https://www.medrxiv.org/ content/10.1101/2020.02.08.20021253v2.full.pdf; L.Zhang et al., unpub. data, https:/ / www.medrxiv. org/content/10.1101/2020.02.16.20023804v1; C.C. $\mathrm{Ku}$ et al., unpub. data, https://papers.ssrn.com/ sol3/papers.cfm?abstract_id $=3543589 ;$ C. Wang et al., unpub. data, https://www.medrxiv.org/cont ent/10.1101/2020.03.03.20030593v1.full.pdf; K.C. Chong et al., unpub. data, https://www.medrxiv. org/content/10.1101/2020.03.02.20028704v1.full. pdf; D. Chen and T. Zhou, unpub data, https:// arxiv.org/pdf/2003.00305v1.pdf). In Singapore and South Korea, declines in $R$ estimates also suggest decreases in transmission: from 1.1 to 0.7 as of February 14 in Singapore, and 1.5 (95\% CI 1.4-1.6) in South Korea up to February 27 (28; A. Tariq et al., unpub. data, https://www.medrxiv.org/conte nt/10.1101/2020.02.21.20026435v6.full.pdf). The R estimate for the Diamond Princess cruise ship suggests high transmission before and immediately after movement restrictions on the ship (median R 12.1 [95\% CrI 8.2-17.2] on February 7, 2 days postquarantine), with rapid decrease thereafter (median $\mathrm{R}$ 0.35 [95\% CrI 0.02-2.19] as of February 18) (29). Together, these estimates suggest that $R_{0}$ is high, yet intensive interventions can reduce transmissibility (R) substantially.

\section{Peer-reviewed literature}

Backer (30)

Leung $(11,32)$

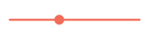

Li (9)

Linton $(31,35)$

Zhang (33)

\section{Gray literature}

Lu (2020)

Tindale (2020a)

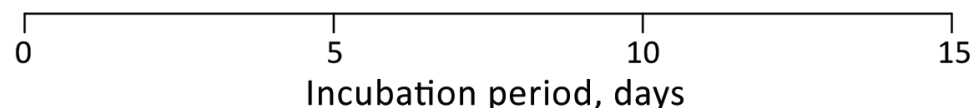

Tindale (2020b)

\section{Incubation Period}

The incubation period is the time between infection and symptom onset. Seven studies (10 estimates) were included in this review; the overall range was 1.8-9.0 days (Figure 2; Appendix Tables 2, 3) (9,30-33; L. Tindale et al., unpub. data, https:// www.medrxiv.org/content/10.1101/2020.03.03.20 029983v1; H. Lu et al., unpub. data, https://www. medrxiv.org/content/10.1101/2020.02.19.200250 $31 v 1$ ). Among the articles in peer-reviewed literature, the mean incubation period was 1.8-6.9 days $(9,30-33)$.

\section{Serial Interval}

The serial interval is the average time between symptom onset of a primary and transmission associated secondary case. Seven studies (10 estimates) estimated the mean serial interval in the range of 4.0-7.5 days (Figure 3; Appendix Tables 2, 3) (9,33-36; L. Tindale et al., unpub. data, https:/ / www.medrxiv.org/conte nt/10.1101/2020.03.03.20029983v1; S. Zhao et al., unpub. data, https://www.medrxiv.org/content/10.11 01/2020.02.21.20026559v1). Ganyani et al. estimated a mean generation interval of 5.21 in Singapore and 3.95 in Tianjin, China (36).

\section{Doubling Time}

The doubling time is the average time for the daily case count to double. Using both genetic and case data over several locations and time periods,

Figure 2. Estimated incubation period for
- Mean $\Delta$ Median coronavirus disease based on search in peer-reviewed and gray literature. Error bars indicate confidence (blue) or credible (red) intervals. Gray literature sources: Lu et al., unpub. data, https://www.medrxiv. org/content/10.1101/2020. 02.19.20025031v1, Tindale et al., unpub. data, https:// www.medrxiv.org/content/ $10.1101 / 2020.03 .03 .20029$ $983 \mathrm{v} 1$ (also see Appendix Tables 2, 3). 
Peer-reviewed literature

Du (34)

Ganyani (36)

Li (9)

Nishiura (35)

Zhang (33)

Gray literature

Tindale (2020a)

Tindale (2020b)

\begin{tabular}{c|c}
$\longrightarrow$ & 0 \\
-5 & 0
\end{tabular}

Zhao (2020b)
- Mean

$\Delta$ Median
Figure 3. Estimated serial interval for coronavirus disease based on search in peerreviewed and gray literature. Error bars indicate confidence (blue) or credible (red) intervals. Gray literature sources: Tindale et al., unpub. data, https://www. medrxiv.org/content/10.1101/2 020.03.03.20029983v1, Zhao et al., unpub. data, https://www. medrxiv.org/content/10.1101/20 20.02.21.20026559v1 (also see Appendix Tables 2, 3).

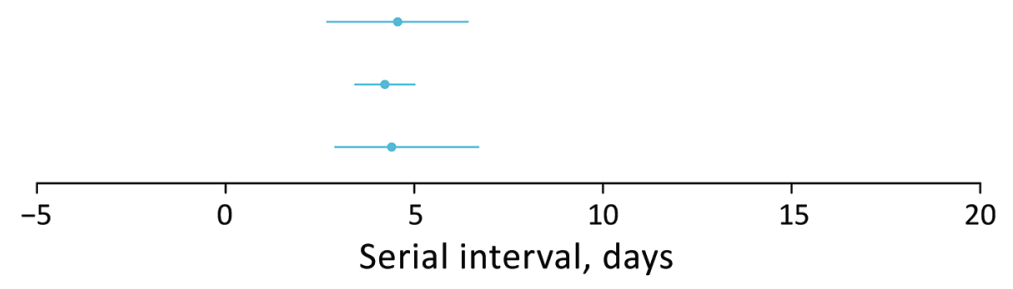

11 studies estimated a mean doubling time of 2.3-7.4 days (Figure 4, Appendix Tables 2,3) $(9,11,15,17,18,21$; A. Rambaut, unpub. data, http://virological.org/t/ phylodynamic-analysis-176-genomes-6-mar-2020/356; T. Bedford, unpub. data, http://virological.org/t/ phylodynamic-estimation-of-incidence-and-prevalence-of-novel-coronavirus-ncov-infections-

through-time/391; F. Pinottiet al., unpub. data, https:/ / www.medrxiv.org/content/10.1101/2020.02.24.200 27326v1; S. Zhao et al., unpub. data, https://www. medrxiv.org/content/10.1101/2020.02.06.20020941v1; Volz et al., unpub. data, https://spiral.imperial.ac.uk/ bitstream/10044/1/77169/11/2020-02-15-COVID19Report-5.pdf).
Figure 4. Estimated doubling time for coronavirus disease based on search in peerreviewed literature and gray literature. Error bars indicate confidence (blue) or credible (red) intervals. Gray literature sources: Onset: Zhao et al., unpub. data, https://www.medrxiv. org/content/10.1101/2020.02.06.2 0020941v1 ; report: Pinotti et al., unpub. data, https://www.medrxiv. org/content/10.1101/2020.02.24. 20027326v1 ; sample collection: Bedford, unpub. data, http:// virological.org/t/phylodynamicestimation-of-incidence-andprevalence-of-novel-coronavirusncov-infections-through-time/3 , Rambaut, unpub. data, http:// virological.org/t/phylodynamicanalysis-176-genomes-6mar-2020/356, Rambaut, unpub. data, http://virological. org/t/phylodynamic-analysis-

176-genomes-6-mar-2020/356

(same), Volz et al., https://spiral.

imperial.ac.uk/bitstream/10044/1/77169/11/2020-02-15-COVID19-Report-5.pdf (also see Appendix Tables 2, 3).

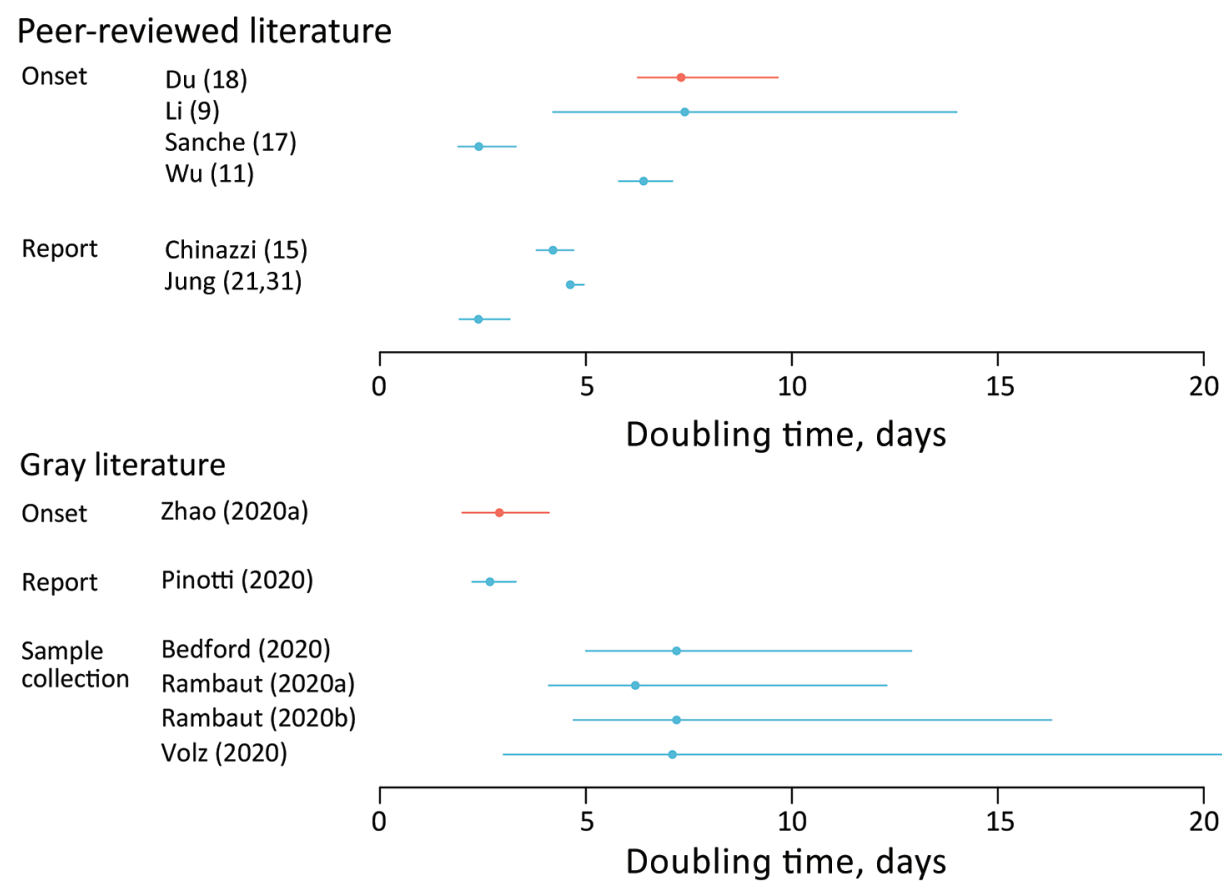




\section{Infectious Period}

The infectious period is the period of time in which an infected host, with or without symptoms, can transmit to susceptible persons. One estimate (C. You et al., unpub. data, https://www.medrxiv.org/content $/ 10.1101 / 2020.02 .08 .20021253 \mathrm{v} 2)$, based on data from 67 cases, estimated a mean infectious period of 10.91 days (SD 3.95 days). Little is known about how characteristics of an infected person, such as age, severity, and clinical progression, affect overall infectious period estimates.

\section{Severity}

We did not identify mathematical or statistical models that examine clinical disease progression. We include empiric findings detailed in the WHO China Mission report, which has been used to inform other models (37).

Most of the $>75,000$ cases of COVID-19 reported through March 6 were from Hubei Province. Among 55,924 confirmed cases in China as of February 20, the median patient age was 51 years (range 2 days-100 years); most $(77.8 \%)$ patients were $30-69$ years of age. The clinical distribution was $80.4 \%$ mild/moderate, $13.8 \%$ severe, and $6.1 \%$ critically ill (Appendix Table 4 ). Only $2.4 \%$ of reported cases were among persons $<19$ years of age (37). Severe disease was reported among those with increased age (>60 years) and underlying conditions such as hypertension, diabetes, cardiovascular disease, chronic respiratory disease, and cancer (38). Fatality estimates have come primarily from elderly Wuhan residents (39), suggesting substantially higher lethality compared with cases outside Hubei Province (Figure 5).

The age distribution of cases and deaths detected outside China has been wider than that within China (39). This difference may result from highersensitivity surveillance for travelers compared with cases inside China, particularly in countries on high alert, such as Thailand and Japan, which implemented temperature screening at airports. In general, early severe cases were more likely to be detected than mild cases, resulting in higher severity estimates early on. Cases among travelers might also generally be in younger persons because of age-specific differences in travel.

A broader spectrum of clinical severity has been observed in travel-associated and locally acquired cases reported outside China, likely reflecting more robust surveillance for SARS-CoV-2. Severity ranges from asymptomatic infection to symptoms such as fever and fatigue, as well as mild to severe respiratory symptoms including cough and pneumonia. Cases have been reported in persons with previously good health and no known underlying conditions (40). Differences in severity have also been observed within transmission chains (41-44).

The case-fatality ratio (CFR) is the proportion of cases that result in death. There are several variations of CFR, including symptomatic (sCFR), laboratoryconfirmed (cCFR), hospitalization (HFR), critical care (cCCFR), and infection (IFR). Eleven studies, estimating either CFR or a variation of CFR, were included in this review (Figure 5). Most estimates were based on data from China; however, a few are from outside China or from the Diamond Princess cruise ship $(39,45)$. Estimates of CFR generally did not include specific case definitions and ranged from $0.9 \%$ to $18.9 \%$. Moreover, CFR is highly variable across situations (e.g., general population, hospitalized patients, or critically ill patients). Critically ill patients' estimates range between $8.0 \%$ and $28.7 \%$ (X. Deng et al., unpub. data, https://www.medrxiv.org/content/10 $.1101 / 2020.03 .04 .20031005 v 1)$. Notably, IFR seems to be more consistent across studies, with central estimates around $0.6 \%$ in 2 peer-reviewed studies from mainland China $(39,45)$, yet higher at $3.3 \%$ in Hubei Province and $3 \%$ in northern Italy (A. Hauser et al., unpub. data, https://www.medrxiv.org/content/ medrxiv / early/2020/03/30/2020.03.04.20031104. full.pdf), and lower at $0.2 \%-1.6 \%$ in Asia and Europe (Figure 5; Appendix Table 5).

There was evidence of a strong age gradient in both CFR and IFR; elderly patients were at higher risk (43). IFR shows a strong age gradient; IFR was $0.007 \%$ in children, $1.9 \%-4.6 \%$ in patients $60-69$ years of age, and $7.8 \%-18 \%$ in patients $>80$ years of age (39). Hospitalization rates were also age dependent: $<0.04 \%$ in children, $11.8 \%$ in patients $60-69$ years of age, and $18.4 \%$ among patients $\geq 80$ years of age (39).

\section{Viral Evolution and Genomic Epidemiology}

Virus genome sequences from a representative sample of cases can be used for calculating the evolutionary rate, date of introduction to the human population, and size of outbreak, as well as estimating the reproduction number and doubling time (46-49). The evolutionary rate is the rate at which mutations accumulate per base pair in the genome over the course of a year. Estimates have ranged from $0.8 \times 10^{-3}$ to 1.2 $\times 10^{-3}$ (Table 2; J. Sciré et al., unpub. data, http:// virological.org/t/update-2-evolutionary-epidemiological-analysis-of-128-genomes/423; S. Duchene et al., unpub. data, http:/ / virological.org/t/temporal-signal-and-the-evolutionary-rate-of-2019-n-covusing-47-genomes-collected-by-feb-01-2020/379; 


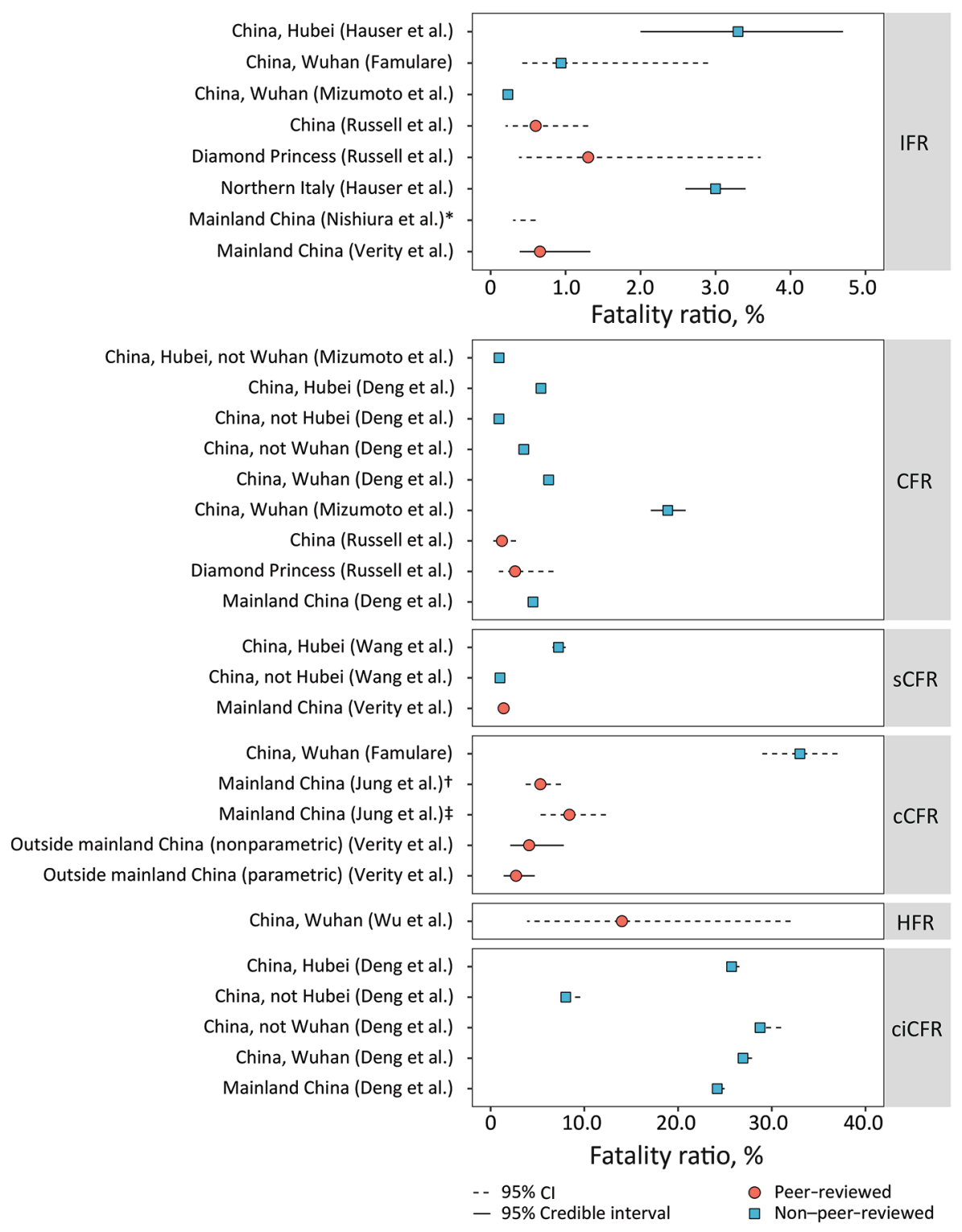

Figure 5. Summary of IFR and CFR estimates for coronavirus disease. Circles or squares indicate mean or median estimates and error bars indicate confidence (dotted line) or credible (full line) intervals. Red indicates peer-reviewed and blue nonpeer-reviewed papers (for links to non-peer reviewed papers, see Appendix Table 5). *Range based on $\approx 10 \%$ ascertainment. †Epidemic growth alone. \#Epidemic growth along with other parameters. CFR, case fatality ratio; cCFR, laboratory-confirmed CFR; CCCFR, critical care and severe CFR; sCFR, symptomatic CFR; HFR, hospitalization fatality ratio; IFR, infection fatality ratio.

V. Hill and A. Rambaut, unpub. data, https:// virological.org/t/ phylodynamic-analysis-ofsars-cov-2-update-2020-03-06/420; A. Rambaut, unpub.data,http://virological.org/t/phylodynamicanalysis-176-genomes-6-mar-2020/356; T. Bedford, unpub. data, http://virological.org/t/phylodynamic-estimation-of-incidence-and-prevalenceof-novel-coronavirus-ncov-infections-throughtime/391). These evolutionary rates are similar to those of MERS-CoV and SARS-CoV-1. The data suggest that the COVID-19 outbreak was started by a single spillover event occurring in late 2019 (Table 2) and supported by case-reported data in December 2019 (50; J. Sciré et al., unpub. data, http:/ / virological.org/t/update-2-evolutionary-epidemiological- analysis-of-128-genomes/423; S. Duchene et al., unpub. data, http://virological.org/t/temporalsignal-and-the-evolutionary-rate-of-2019-n-covusing-47-genomes-collected-by-feb-01-2020/379; V. Hill and A. Rambaut, unpub. data, http://virological.org/t/phylodynamic-analysis-of-sars-cov2-update-2020-03-06/420; A. Rambaut, unpub. data, http:/ / virological.org/t/phylodynamic-analysis176-genomes-6-mar-2020/356; T. Bedford, unpub. data, http://virological.org/t/phylodynamic-estimation-of-incidence-and-prevalence-of-novel-coronavirus-ncov-infections-through-time/391; Volz et al., unpub. data, https://spiral.imperial.ac.uk/ bitstream/10044/1/77169/11/2020-02-15-COVID19-Report-5.pdf). 
Table 2. Summary of estimates of mean evolutionary rate and most recent common ancestor of COVID-19*

\begin{tabular}{|c|c|c|c|c|c|}
\hline $\begin{array}{l}\text { Mean evolutionary rate } \\
(95 \% \mathrm{Cl})\end{array}$ & MRCA $(95 \% \mathrm{Cl})$ & $\begin{array}{c}\text { No. } \\
\text { genomes } \\
\text { analyzed }\end{array}$ & $\begin{array}{c}\text { Clock } \\
\text { model† }\end{array}$ & $\begin{array}{l}\text { Growth } \\
\text { model }\end{array}$ & Source \\
\hline NA & $\begin{array}{c}2019 \text { Nov 29 } \\
\text { (Nov 8-Dec 16) }\end{array}$ & 23 & Strict & Constant & $\begin{array}{l}\text { Rambaut, unpub. data, } \\
\text { http://virological.org/t/phylogenetic-analysis-of-23- } \\
\text { ncov-2019-genomes-2020-01-23/335 }\end{array}$ \\
\hline $\begin{array}{l}1.23 \times 10^{-3}\left(0.56 \times 10^{-3}\right. \\
\left.\text { to } 1.98 \times 10^{-3}\right)\end{array}$ & $\begin{array}{c}2019 \text { Nov } 21 \text { (Oct } \\
\text { 23-Dec 13) }\end{array}$ & 51 & Strict & Exponential & $\begin{array}{l}\text { Duchene et al., unpub. data, } \\
\text { http://virological.org/t/temporal-signal-and-the- } \\
\text { evolutionary-rate-of-2019-n-cov-using-47- } \\
\text { genomes-collected-by-feb-01-2020/379 }\end{array}$ \\
\hline $\begin{array}{l}1.29 \times 10^{-3}(0.535 \times \\
\left.10^{-4} \text { to } 2.15 \times 10^{-3}\right)\end{array}$ & $\begin{array}{c}2019 \text { Nov } 14 \text { (Sep } \\
28-\operatorname{Dec} 13)\end{array}$ & 51 & UNCL & Exponential & $\begin{array}{l}\text { Duchene et al., unpub. data, } \\
\text { http://virological.org/t/temporal-signal-and-the- } \\
\text { evolutionary-rate-of-2019-n-cov-using-47- } \\
\text { genomes-collected-by-feb-01-2020/379 }\end{array}$ \\
\hline $\begin{array}{l}0.9 \times 10^{-3}\left(0.5 \times 10^{-3} \text { to }\right. \\
\left.1.4 \times 10^{-3}\right)\end{array}$ & $\begin{array}{c}2019 \text { Dec } 3 \text { (Oct } \\
\text { 30-Dec 17) }\end{array}$ & 51 & Strict & Exponential & $\begin{array}{l}\text { Bedford, unpub. data, } \\
\text { http://virological.org/t/phylodynamic-estimation-of- } \\
\text { incidence-and-prevalence-of-novel-coronavirus- } \\
\text { ncov-infections-through-time/391 }\end{array}$ \\
\hline $\begin{array}{l}0.92 \times 10^{-3}\left(0.33 \times 10^{-3}\right. \\
\left.\text { to } 1.46 \times 10^{-3}\right)\end{array}$ & $\begin{array}{l}2019 \text { Nov } 29 \text { (Oct } \\
28-\operatorname{Dec} 20)\end{array}$ & 75 & Strict & Exponential & $\begin{array}{l}\text { Rambaut, unpub. data, } \\
\text { http://virological.org/t/phylodynamic-analysis-176- } \\
\text { genomes-6-mar-2020/356. Accessed March 4, } \\
2020\end{array}$ \\
\hline $\begin{array}{l}1.04 \times 10^{-3}\left(0.71 \times 10^{-3}\right. \\
\left.\text { to } 1.4 \times 10^{-3}\right)\end{array}$ & $\begin{array}{c}2019 \text { Dec } 3 \text { (Nov } \\
16-\operatorname{Dec} 17)\end{array}$ & 116 & Strict & Exponential & $\begin{array}{l}\text { Hill and Rambaut, unpub. data, } \\
\text { http://virological.org/t/phylodynamic-analysis-of- } \\
\text { sars-cov-2-update-2020-03-06/420 }\end{array}$ \\
\hline $\begin{array}{l}7.41 \times 10^{-4}\left(4.91 \times 10^{-4}\right. \\
\left.\text { to } 1.02 \times 10^{-3}\right)\end{array}$ & $\begin{array}{l}2019 \text { Nov } 27 \text { (Nov } \\
\text { 7-Dec 11) }\end{array}$ & 128 & Strict & $\begin{array}{l}\text { Birth-death } \\
\text { model }\end{array}$ & $\begin{array}{l}\text { Sciré et al., unpub. data, } \\
\text { http://virological.org/t/update-2-evolutionary- } \\
\text { epidemiological-analysis-of-128-genomes/423 }\end{array}$ \\
\hline
\end{tabular}

\section{Effectiveness of Nonpharmaceutical Interventions}

Nonpharmaceutical interventions (NPIs) include interventions at individual and community levels. At the individual level, NPIs examined in modeling studies included voluntary home isolation or quarantine (Appendix Table 6). At the community level, NPIs included school and workplace closures and canceling or postponing large public gatherings (see Appendix Table 7 for definitions). Modeling can be used to estimate the effectiveness of components of these interventions (e.g., case detection), the interventions themselves (e.g., case isolation) or combinations of interventions (e.g., case and contact isolation). In total, 29 articles were identified; of these, 17 met the inclusion criteria for this review (Table 3) $(11,15,18,51-56$; F. Pinotti et al., unpub. data, https:/ / www.medrxiv.org/ content/10.1101/2020.02.24.20027326v1; R. Niehus et al., unpub. data, K. Gostic et al., unpub. data, https:/ / www.medrxiv.org/content/10.1101/2020.01.28.2001 9224v2; A. Adiga et al., unpub. data, https://www. medrxiv.org/content/10.1101/2020.02.20.2002588 2v2; S. Lai et al., unpub. data, https://www.medrxiv.org/content/10.1101/2020.03.03.20029843v3.full. pdf; Y. Zhang et al., unpub. data, https://www.medrxiv.org/content/10.1101/2020.03.04.20031187v1; S. Clifford et al., unpub. data, https:/ / cmmid.github. io/topics/covid19/screening-outbreak-delay.html;
S. Bhatia et al., unpub. data, https://www.imperial. ac.uk/media/imperial-college/medicine/sph/ide/ gida-fellowships/Imperial-College-COVID19-international-surveillance-21-02-2020.pdf).

\section{Case Screening and Detection}

Recent articles have addressed the efficacy of screening and detection by surveillance systems in different countries (51; F. Pinotti et al., unpub. data, https:/ / www.medrxiv.org/content/10.1101/2020.02.24.2 0027326v1; R. Niehus et al., unpub. data, https:// www.medrxiv.org/content/10.1101/2020.02.13.200 22707v2; S. Bhatia et al., unpub. data_https://www. imperial.ac.uk/media/imperial-college/medicine/ sph/ide/gida-fellowships/Imperial-College-COVID19-international-surveillance-21-02-2020.pdf). Two studies used data from Singapore (known for having a reliable health reporting system) as benchmarks to estimate the sensitivity of surveillance systems in other countries (R. Niehus et al., unpub. data, https:// www.medrxiv.org/content/10.1101/2020.02.13.2002 2707v2; S. Bhatia et al., unpub. data,_https://www. imperial.ac.uk/media/imperial-college/medicine/ sph/ide/gida-fellowships/Imperial-College-COVID19-international-surveillance-21-02-2020.pdf). Both articles agreed that only a fraction of cases $(22 \%-64 \%)$ are captured by surveillance systems, varying by 
country. A more recent study found similar results (36\% detected cases), and lower ascertainment when repatriations were considered (F. Pinotti et al., unpub. data, https://www.medrxiv.org/content/10.1101/2 020.02.24.20027326v1).

\section{Case Isolation and Quarantine of Contacts}

One study considered different scenarios in which the reproduction number and transmission before symptom onset were varied to study the controllability of the outbreak (51). The authors found that as $R_{0}$ increased, the percentage of contacts to be traced increased. The delay between symptom onset and isolation also affected the controllability of the outbreak. For values of $\mathrm{R}_{0}>2.5$, contact tracing and isolation were successful at stopping transmission when $<1 \%$ of transmission occurred before symptom onset. For these 2 parameters, case isolation alone would be unlikely to control transmission within 3 months.

\begin{tabular}{ll}
\hline \multicolumn{2}{l}{ Table 3. Summary of studies of NPIs for COVID-19 } \\
\hline NPI & Summary/results \\
\hline Case detection & $(27 \%-37 \%)$ cases detected $†$
\end{tabular}

Case detection $\quad 38 \%(22 \%-64 \%)$ cases detected

Case screening $\quad(36 \%-65 \%)$ cases detected $†$
and detection

\begin{tabular}{|c|c|}
\hline $\begin{array}{l}\text { Case isolation and } \\
\text { contact tracing }\end{array}$ & $\begin{array}{l}\text { Delay of symptom onset to isolation has a high impact } \\
\text { on the results, affecting the controllability of the } \\
\text { outbreak. Results vary by scenario. }\end{array}$ \\
\hline Travel screening & $\begin{array}{l}34 \%(20 \%-50 \%) \text { of travelers identified through both } \\
\text { departure and arrival screening using symptoms or risk } \\
\text { screening }\end{array}$ \\
\hline Travel screening & $\begin{array}{l}46.5 \%(35.9 \%-57.7 \%) \text { travelers not detected through } \\
\text { thermal screening }\end{array}$ \\
\hline Travel screening & $\begin{array}{l}\text { Syndromic screening and traveler sensitization in } \\
\text { combination could delay outbreaks in yet unaffected } \\
\text { countries up to } 83 \mathrm{~d}(75 \% 36 \mathrm{~d}, 97.5 \% 8 \mathrm{~d}) \text {. }\end{array}$ \\
\hline $\begin{array}{l}\text { Travel reduction } \\
\text { (transport } \\
\text { suspension) }\end{array}$ & $\begin{array}{l}\text { Delay of } 2.91 \mathrm{~d}(95 \% \mathrm{Cl} 2.54-3.29) \text { for the arrival of th } \\
\text { disease to other cities in China }\end{array}$ \\
\hline $\begin{array}{l}\text { Travel reduction } \\
\text { (travel quarantine) }\end{array}$ & $\begin{array}{l}130 \text { cities in China had } \geq 50 \% \text { chance of having a } \\
\text { COVID- } 19 \text { case imported from Wuhan in the } 3 \text { weeks } \\
\text { preceding the quarantine. }\end{array}$ \\
\hline Travel restrictions & $\begin{array}{l}\text { Travel restriction imposed on Wuhan delay the } \\
\text { epidemic for } 3 \mathrm{~d} \text {. }\end{array}$ \\
\hline $\begin{array}{l}\text { Travel reduction } \\
\text { (airline } \\
\text { suspensions) }\end{array}$ & $\begin{array}{l}\text { Travel restriction imposed on China will delay the } \\
\text { disease in other countries, the biggest delay being in } \\
\text { Africa }(11 \mathrm{~d}) \text { and South America }(9 \mathrm{~d}) \text {. }\end{array}$ \\
\hline Tra & mic for $2 \mathrm{~d}$ \\
\hline & $\begin{array}{l}37 \% \text { fewer cases when the interventions started before } \\
\text { the first case }\end{array}$ \\
\hline & $6 \%, 86 \%$, and $95 \%$ fewer cases depending on timing \\
\hline
\end{tabular}

Combination of NPI $50 \%$ fewer cases if transmissibility reduced by $25 \%$ in all cities in China; delay of epidemic peak for 1 month

Combination of NPI Drastic control measures implemented in China have substantially mitigated spread of COVID-19.

Combination of NPI Earlier intervention of social distancing could limit the epidemic in mainland China. Number of infections could be reduced up to $98.9 \%$, and number of deaths could be reduced by up to $99.3 \%$ as of Feb 23, 2020.

Community At least $42 \%$ of persons interviewed have modified behavior modification daily behavior.

\section{Source/reference}

Bhatia et al., unpub. data

https://www.imperial.ac.uk/media/imperial-

college/medicine/sph/ide/gida-fellowships/ImperialCollege-COVID19-international-surveillance-21-022020.pdf

Niehus et al., unpub. data,

https://www.medrxiv.org/content/10.1101/2020.02.13.2 0022707v2

Pinotti et al., unpub. data,

https://www.medrxiv.org/content/10.1101/2020.02.24.2 $0027326 \mathrm{v} 1$

\section{(51)}

Gostic et al., unpub. data,

https://www.medrxiv.org/content/10.1101/2020.01.28.2 0019224v2

(52)

Clifford et al., unpub. data,

https://cmmid.github.io/topics/covid19/screeningoutbreak-delay.html (53)

Adiga et al., unpub. data, https://www.medrxiv.org/content/10.1101/2020.02.20.2 0025882v2

Lai et al., upub. data, https://www.medrxiv.org/content/10.1101/2020.03.03.2 0029843v3.full.pdf

Zhang et al., unpub. data, https://www.medrxiv.org/content/10.1101/2020.03.04.2 $0031187 v 1$

*COVID-19, coronavirus disease; NPI, nonpharmaceutical interventions.

†Point estimates 


\section{Traveler Screening}

Two studies considered models in which passengers were screened before leaving an area with local transmission and upon arrival at their destination (52; K. Gostic et al., unpub. data, https:/ / www. medrxiv.org/content/10.1101/2020.01.28.2001922 $4 \mathrm{v} 2$ ), demonstrating that a relatively low number of cases would likely be detected (34\%-54\%). Different factors affect the underdetection of cases, including the country's ability to detect cases. Some of those factors include asymptomatic infections, infections with mild clinical symptoms, limited care-seeking behavior, case definition, and underrecognition of cases by clinicians. A third study suggests that exit and entry screening combined with traveler sensitization can delay a local outbreak by $\geq 83$ days, with $\leq 1$ infected traveler per week (S. Clifford et al., unpub. data, https://cmmid.github.io/topics/covid19/screening-outbreak-delay.html).

\section{Travel Restrictions}

On January 23, 2020, travel bans were implemented from Wuhan city. Within China, this resulted in a delay in disease arrival of 3 days, on average (53). Cities that implemented the ban before their first case was detected observed fewer cases than cities that implemented the ban after their first case (53). Another study found that 130 cities in China had $>50 \%$ chance of having a COVID-19 case imported from Wuhan in the 3 weeks preceding the implementation of travel restrictions, suggesting that there were cases outside of Wuhan before the travel ban (18). Analysis of the effect of the Wuhan travel ban, including the implementation of long-range travel restrictions on January 23, showed no noticeable difference for the epidemic trajectory of Wuhan, while delaying the occurrence of cases for other locations in China by 3 days (15). Another study found that travel restrictions would delay the epidemic spread throughout China by 2 days (54).

Internationally, several countries implemented travel bans. One modeling study estimated how travel restrictions from China affected the time of arrival of the infected persons (A. Adiga et al., unpub. data, https://www.medrxiv.org/content/10.1 $101 / 2020.02 .20 .20025882 v 2)$. It found that countries in Africa and South America would likely observe the biggest delays: 11 days for Africa and 9 days for South America. Another study found that travel reductions of up to $90 \%$ had only a modest effect unless paired with public health interventions and behavioral changes to achieve a considerable reduction in disease transmission (15).

\section{Cancellation of Events and Public Gatherings}

One study analyzed a range of interventions, such as suspending public transport, closing entertainment venues, and banning public gatherings (53). Results varied by city and number of control measures adopted; the study found that cities that implemented a level 1 response ( $\geq 2$ control measures) before the first case was confirmed had 37\% fewer cases in the week after the first case identified compared with cities that started control thereafter. Locations that closed entertainment venues and banned public gatherings early in the outbreak reported fewer cases during the first week.

Finally, 4 studies estimated the effects of transmission reduction in China when NPI mitigation strategies were combined (11; S. Lai et al., unpub. data, https://www.medrxiv.org/content/10.1101/2020. 03.03.20029843v3.full.pdf). The combined interventions notably reduced the number of cases observed and delayed the epidemic peak by $>1$ month. It was found that earlier intervention of social distancing could greatly limit the epidemic in mainland China. The number of infections could have been reduced up to $98.9 \%$, and the number of deaths reduced by 99.3\%, as of February 23, 2020 (Y. Zhang et al., unpub. data, https://www.medrxiv.org/content/10.1101/2 020.03.04.20031187v1). A different group found that following the implementation of control measures, growth rates became negative in most locations, and that drastic control measures implemented in China substantially mitigated COVID-19 spread (56).

\section{Community Behavior Modification}

One research group performed an online survey after the first case of COVID-19 was reported in Hong Kong. Those results showed that $39 \%-88 \%$ of the persons surveyed had adopted social distancing measures (55).

\section{Discussion}

Modeling can provide estimates of disease transmission parameters for planning and response during epidemics. Investigators around the world have been trying to understand the transmission dynamics and severity of disease, as well as the effects that different interventions have had on the course of the epidemic through advanced analytics and modeling. However, transmission parameter estimates are limited by the availability and comprehensiveness of data early in the epidemic. Some parameters can be estimated from genetic sequencing data, but these estimates are heavily influenced by biases in sampling and inaccuracies in sequencing. Although efforts to collect and 
share clinical, epidemiologic, and sequence data have been remarkably timely, there remain outstanding gaps in knowledge.

Several parameters presented in this review are context specific, such as $R_{0}$ values or CFR measurements. Although the characteristics of SAR-CoV-2 are unlikely to change, responses to transmission will vary. Several factors affect the trajectory of an epidemic in different locations, such as population density, health system infrastructure, transportation robustness, cultural practices, and poverty levels (57). Available data from China may not be reflective of secular trends elsewhere. As other countries develop more cases, more robust data will be available for modeling and extrapolation for countries not yet affected.

Challenges in assessing severity of clinical outcomes during a new emerging epidemic have been discussed in depth elsewhere and are not covered here $(7,8)$. However, 4 challenges remain. First, early in an outbreak, data are heavily biased toward severe cases. Estimates of the CFR in those patients with known outcomes may be biased upward until the extent of clinically milder disease is determined. Second, there is a period between onset of symptoms and final clinical outcome (death vs. survival) $(58,59)$. During a growing epidemic, the final clinical outcome of most reported cases is typically unknown. This is particularly true with COVID-19, with which severely ill patients may be hospitalized for many days. The crude CFR will underestimate the fatality risk among early epidemic cases $(7,8,59)$. Third, while the epidemic is growing there will be a bias toward having observed cases with recent symptom onset and outcomes. Therefore, estimates should be adjusted for the growth rate of the epidemic (8). Fourth, overrepresentation of men, elderly persons with underlying conditions, and persons with respiratory risk factors (such as smoking) may result from observation bias or exposure differences and affect CFR estimates.

Country preparedness and clinical care capacity will affect patient outcomes. Delayed diagnosis and treatment, limited knowledge of the natural history of infection, and rapid escalation of cases can affect clinical outcomes. Thus, fatality in patients cared for very early in a country's epidemic may be greater than in later patients (7). More information on the proportion of persons requiring healthcare, level of care (outpatient, inpatient, and intensive care), and duration of care required are essential for predicting healthcare needs as the epidemic progresses.

Presymptomatic or asymptomatic transmission, if substantial, might have critical implications for control efforts. Empiric evidence of such potential transmission includes a serial interval and generation time that were estimated shorter than the incubation period (L. Tindale et al., unpub.data, https:/ / www.medrxiv.org/content/10.1101/2020.03.03.2002 9983v1; H. Lu et al., unpub. data, https://www.medrxiv.org/content/10.1101/2020.02.19.20025031v1), similarly high viral loads in asymptomatic and symptomatic cases $(36,60)$, and documentation of patients infected by presymptomatic or asymptomatic carriers in cluster investigations (61-64). If asymptomatic infectious carriers are not characterized appropriately in models, epidemic infection rates would be underestimated but the severity and the effectiveness of interventions would be overestimated, potentially leading to implementation of ineffective interventions. Serologic studies will be critical for understanding the role of asymptomatic transmission.

Early evidence suggests that travel restrictions result in only modest decreases in the importation of cases. However, combined with other social distancing measures and behavior changes, travel restrictions may be a useful addition. Modeling can be extremely valuable in providing counterfactuals aimed at disentangling the effects of different NPIs. Documentation of timing, type of NPI, and compliance rate will be needed to estimate the effectiveness of the different interventions.

This study is subject to additional limitations. To use the latest information, we included a number of preprint reports that have not been formally peer reviewed. In addition, there is a heavy reliance on data from China, because of the period considered. Given the recent geographic spread of COVID-19, there may be a range of future estimates that will differ from those reported here. Finally, we have not performed a formal assessment of possible biases of the estimates examined in this article, and therefore cannot exclude that some estimates reported are affected by unmeasured sources of biases.

As the COVID-19 epidemic progresses, ongoing refinement and validation of key epidemiologic parameters will help inform the global public health response. Defining optimal surveillance methods, laboratory testing, contact tracing parameters, quarantine measures, hospital acute care capacities, and many other operational factors depends on estimates of the epidemiologic parameters summarized in this article. One of the largest knowledge gaps is that of asymptomatic or presymptomatic infectious potential and the occurrence of subclinical infections. In the absence of efficacious vaccines and therapeutics, developing an evidence base for NPIs will remain a critical tool for 
effective local, national, and global outbreak control. Better data will enable mathematical and statistical modeling to more precisely predict how different NPIs can be combined to produce efficient epidemic control.

Our summary provides estimates through the first 10 weeks of the COVID-19 epidemic that are needed for operational planning, scenario-building for contingency planning, and forecasting to inform today's preparedness and response efforts. Data from outbreaks in newly affected countries and new data stemming from seroprevalence and transmission studies will provide insights currently unavailable. Documenting and evaluating NPIs will help public health and government decision makers to implement the most effective epidemic control measures.

\section{Acknowledgments}

We appreciate Nicole Samay for assistance with the figures and Xin Tang for the review of Chinese language papers.

N.I., N.F., and Z.C. acknowledge joint center funding from the UK Medical Research Council and Department for International Development, grant no. MR/R015600/1.

The WHO COVID-19 Modelling Parameters Group has convened since January 2020 to discuss and summarize current knowledge on parameters of transmission, severity, and effectiveness of interventions important to support the projection of this epidemic and to inform policy decisions. The group comprises infectious disease modelers and epidemiologists involved in the response to COVID-19.

\section{About the Author}

Dr. Biggerstaff is an epidemiologist with the Centers for Disease Control and Prevention, Atlanta, GA, USA, working on influenza forecasting and modeling activities. His research interests include working to understand and evaluate how forecasting and mathematical modeling can complement influenza surveillance and inform seasonal and pandemic influenza public health actions.

\section{References}

1. World Health Organization. Novel coronavirus (2019-nCoV) situation report 1. 2020 Jan [cited 2020 Mar 1]. https://www. who.int/docs/default-source/coronaviruse/situationreports / 20200121-sitrep-1-2019-ncov.pdf?sfvrsn=20a99c10_4

2. World Health Organization. Coronavirus disease 2019 (COVID-19) situation report 47. 2020 Mar [cited 2020 Mar 1]. https:/ / www.who.int/docs/default-source/coronaviruse/situation-reports/20200307-sitrep-47-covid-19. pdf?sfvrsn=27c364a4_4

3. World Health Organization Health Emergencies Programme. Q\&A on coronaviruses (COVID-19). 2020 [cited 2020 Feb 26]. https:/ / www.who.int/ news-room/q-a-detail/ q-a-coronaviruses
4. Wu JT, Cowling BJ. The use of mathematical models to inform influenza pandemic preparedness and response. Exp Biol Med (Maywood). 2011;236:955-61. https:// doi.org/ 10.1258/ebm.2010.010271

5. Garske T, Cori A, Ariyarajah A, Blake IM, Dorigatti I, Eckmanns T, et al. Heterogeneities in the case fatality ratio in the West African Ebola outbreak 2013-2016. Philos Trans R Soc Lond B Biol Sci. 2017;372:20160308. http:/ / doi.org/ 10.1098/rstb.2016.0308

6. Kucharski AJ, Edmunds WJ. Case fatality rate for Ebola virus disease in west Africa. Lancet. 2014;384:1260. https:/ / doi.org/ 10.1016/S0140-6736(14)61706-2

7. Lipsitch M, Donnelly CA, Fraser C, Blake IM, Cori A, Dorigatti I, et al. Potential biases in estimating absolute and relative case-fatality risks during outbreaks. PLoS Negl Trop Dis. 2015;9:e0003846. https:// doi.org/10.1371/ journal.pntd.0003846

8. Ghani AC, Donnelly CA, Cox DR, Griffin JT, Fraser C, Lam $\mathrm{TH}$, et al. Methods for estimating the case fatality ratio for a novel, emerging infectious disease. Am J Epidemiol. 2005;162:479-86. https:// doi.org/10.1093/aje/kwi230

9. Li Q, Guan X, Wu P, Wang X, Zhou L, Tong Y, et al. Early transmission dynamics in Wuhan, China, of novel coronavirus-infected pneumonia. N Eng J Med. 2020; 382:1199-1207. https://doi.org/10.1056/NEJMoa2001316

10. Zhou T, Liu Q, Yang Z, Liao J, Yang K, Bai W, et al. Preliminary prediction of the basic reproduction number of the Wuhan novel coronavirus 2019-nCoV. J Evid Based Med. 2020;13:3-7. https:// doi.org/10.1111/jebm.12376

11. Wu JT, Leung K, Leung GM. Nowcasting and forecasting the potential domestic and international spread of the 2019nCoV outbreak originating in Wuhan, China: a modelling study. Lancet. 2020;395:689-97. http:/ / dx.doi.org/10.1016/ S0140-6736(20)30260-9

12. Abbott S, Hellewell J, Munday J, Funk S; CMMID nCoV Working Group. The transmissibility of novel coronavirus in the early stages of the 2019-20 outbreak in Wuhan: exploring initial point-source exposure sizes and durations using scenario analysis. Wellcome Open Res. 2020;5:17. http://dx.doi.org/10.12688/wellcomeopenres.15718.1

13. Anastassopoulou C, Russo L, Tsakris A, Siettos C. Databased analysis, modelling and forecasting of the COVID-19 outbreak. PLoS ONE. 2020;15:e0230405. https://doi.org/ 10.1371/journal.pone.0230405

14. Riou J, Althaus CL. Pattern of early human-to-human transmission of Wuhan 2019 novel coronavirus (2019-nCoV), December 2019 to January 2020. Eurosurveillance. 2020 Jan 30 [cited 2020 Mar 6]. https:/ / www.eurosurveillance.org/ content/10.2807/1560-7917.ES.2020.25.4.2000058

15. Chinazzi M, Davis JT, Ajelli M, Gioannini C, Litvinova M, Merler S, et al. The effect of travel restrictions on the spread of the 2019 novel coronavirus (COVID-19) outbreak. Science. 2020;368:395-400. https://doi.org/10.1126/science.aba9757

16. Zhao S, Lin Q, Ran J, Musa SS, Yang G, Wang W, et al. Preliminary estimation of the basic reproduction number of novel coronavirus (2019-nCoV) in China, from 2019 to 2020: a data-driven analysis in the early phase of the outbreak. Int J Infect Dis. 2020;92:214-7. https:/ / doi.org/10.1016/ j.ijid.2020.01.050

17. Sanche S, Lin YT, Xu C, Romero-Severson E, Hengartner $\mathrm{N}$, Ke R. High contagiousness and rapid spread of severe acute respiratory syndrome coronavirus 2. Emerg Infect Dis. 2020;26:1470-7. https:// doi.org/10.3201/eid2607.200282

18. Du Z, Wang L, Cauchemez S, Xu X, Wang X, Cowling BJ, et al. Risk for transportation of 2019 novel coronavirus disease from Wuhan to other cities in China. Emerg 
Infect Dis. 2020;26:1049-52. https://doi.org/10.3201/ eid2605.200146

19. Bi Q, Wu Y, Mei S, Ye C, Zou X, Zhang Z, et al. Epidemiology and transmission of COVID-19 in 391 cases and 1286 of their close contacts in Shenzhen, China: a retrospective cohort study. Lancet Infect Dis. 2020 Apr 27 [Epub ahead of print]. https://doi.org/10.1016/ S1473-3099(20)30287-5

20. Song QQ, Zhao H, Fang LQ, Liu W, Zheng C, Zhang Y. Study on assessing early epidemiological parameters of COVID-19 epidemic in China [in Chinese]. Zhonghua Liu Xing Bing Xue Za Zhi. 2020;41:461-5.

21. Jung SM, Akhmetzhanov AR, Hayashi K, Linton NM, Yang Y, Yuan B, et al. Real-time estimation of the risk of death from novel coronavirus (COVID-19) infection: inference using exported cases. J Clin Med. 2020;9:523. https://doi.org/10.3390/jcm9020523

22. Zhang S, Diao M, Yu W, Pei L, Lin Z, Chen D. Estimation of the reproductive number of novel coronavirus (COVID-19) and the probable outbreak size on the Diamond Princess cruise ship: a data-driven analysis. Int J Infect Dis. 2020;93:201-4. https:/ / doi.org/10.1016/j.ijid.2020.02.033

23. Lloyd-Smith JO, Schreiber SJ, Kopp PE, Getz WM. Superspreading and the effect of individual variation on disease emergence. Nature. 2005;438:355-9. https:/ / doi.org/10.1038/nature04153

24. Kucharski AJ, Althaus CL. The role of superspreading in Middle East respiratory syndrome coronavirus (MERS-CoV) transmission. Eurosurveillance. 2015; 20:21167. https:// doi.org/10.2807/1560-7917. ES2015.20.25.21167

25. Liu Y, Eggo RM, Kucharski AJ. Secondary attack rate and superspreading events for SARS-CoV-2. Lancet. 2020;395:e47. https:/ / doi.org/10.1016/S0140-6736(20)30462-1

26. Kucharski AJ, Russell TW, Diamond C, Liu Y, Edmunds J, Funk S, et al.; Centre for Mathematical Modelling of Infectious Diseases COVID-19 working group. Early dynamics of transmission and control of COVID-19: a mathematical modelling study. Lancet Infect Dis. 2020;20:553-8. https:/ / doi.org/10.1016/S1473-3099(20)30144-4

27. Lai A, Bergna A, Acciarri C, Galli M, Zehender G. Early phylogenetic estimate of the effective reproduction number of SARS-CoV-2. J Med Virol. 2020;92:675-9. https:/ / doi.org/ 10.1002/jmv. 25723

28. Shim E, Tariq A, Choi W, Lee Y, Chowell G. Transmission potential and severity of COVID-19 in South Korea. Int J Infect Dis. 2020;93:339-44. https:/ / doi.org/10.1016/ j.ijid.2020.03.031

29. Mizumoto K, Chowell G. Transmission potential of the novel coronavirus (COVID-19) onboard the Diamond Princess cruises ship, 2020. Infect Dis Model. 2020;5:264-70. https:/ / doi.org/10.1016/j.idm.2020.02.003

30. Backer JA, Klinkenberg D, Wallinga J. Incubation period of 2019 novel coronavirus (2019-nCoV) infections among travellers from Wuhan, China, 20-28 January 2020. Euro Surveill. 2020;25:2000062. https:/ / doi.org/10.2807/15607917.ES.2020.25.5.2000062

31. Linton NM, Kobayashi T, Yang Y, Hayashi K, Akhmetzhanov AR, Jung SM, et al. Incubation period and other epidemiological characteristics of 2019 novel coronavirus infections with right truncation: a statistical analysis of publicly available case data. J Clin Med. 2020;9:538. https://doi.org/10.3390/jcm9020538

32. Leung C. The difference in the incubation period of 2019 novel coronavirus (SARS-CoV-2) infection between travelers to Hubei and nontravelers: the need for a longer quarantine period. Infect Control Hosp Epidemiol. 2020;41:594-6. https://doi.org/10.1017/ice.2020.81

33. Zhang J, Litvinova M, Wang W, Wang Y, Deng X, Chen $X$, et al. Evolving epidemiology and transmission dynamics of coronavirus disease 2019 outside Hubei province, China: a descriptive and modelling study. Lancet Infect Dis. 2020;20:793-802. https:/ / doi.org/10.1016/ S1473-3099(20)30230-9

34. Du Z, Xu X, Wu Y, Wang L, Cowling BJ, Meyers LA. Serial interval of COVID-19 among publicly reported confirmed cases. Emerg Infect Dis. 2020;26:1341-3. https:// doi.org/ 10.3201/eid2606.200357

35. Nishiura H, Linton NM, Akhmetzhanov AR. Serial interval of novel coronavirus (COVID-19) infections. Int J Infect Dis. 2020;93:284-6. https:// doi.org/10.1016/j.ijid.2020.02.060

36. Ganyani T, Kremer C, Chen D, Torneri A, Faes C, Wallinga J, et al. Estimating the generation interval for coronavirus disease (COVID-19) based on symptom onset data, March 2020. Eurosurveillance. 2020;25:2000257. https://doi.org/10.2807/1560-7917.ES.2020.25.17.2000257

37. WHO-China Joint Mission on COVID-19. Report of the WHO-China Joint Mission on Coronavirus Disease 2019 (COVID-19). 2020 Feb [cited 2020 Mar 1]. https:/ / www.who. int/docs/default-source/coronaviruse/who-china-jointmission-on-covid-19-final-report.pdf

38. Guan W, Ni Z, Hu Y, Liang W, Ou C, He J, et al. Clinical characteristics of coronavirus disease 2019 in China. N Engl J Med. 2020;382:1708-20. https://doi.org/10.1056/ NEJMoa2002032

39. Verity R, Okell LC, Dorigatti I, Winskill P, Whittaker C, Imai $\mathrm{N}$, et al. Estimates of the severity of coronavirus disease 2019: a model-based analysis. Lancet Infect Dis. 2020;20:669_ 77. https:/ / doi.org/10.1016/S1473-3099(20)30243-7

40. Van Cuong L, Giang HTN, Linh LK, Shah J, Van Sy L, Hung TH, et al. The first Vietnamese case of COVID-19 acquired from China. Lancet Infect Dis. 2020;20:408-9. https://doi.org/10.1016/S1473-3099(20)30111-0

41. Pan X, Chen D, Xia Y, Wu X, Li T, Ou X, et al. Asymptomatic cases in a family cluster with SARS-CoV-2 infection. Lancet Infect Dis. 2020;20:410-1. https://doi.org/10.1016/ S1473-3099(20)30114-6

42. Liu Y-C, Liao C-H, Chang C-F, Chou C-C, Lin Y-R. A locally transmitted case of SARS-CoV-2 infection in Taiwan. N Engl J Med. 2020;382:1070-2. https:/ / doi.org/10.1056/ NEJMc2001573

43. Pongpirul WA, Pongpirul K, Ratnarathon AC, Prasithsirikul W. Journey of a Thai taxi driver and novel coronavirus. N Engl J Med. 2020;382:1067-8. https:/ / doi.org/10.1056/NEJMc2001621

44. Phan LT, Nguyen TV, Luong QC, Nguyen TV, Nguyen HT, Le HQ, et al. Importation and human-to-human transmission of a novel coronavirus in Vietnam. N Engl J Med. 2020;382:872-4. https://doi.org/10.1056/ NEJMc2001272

45. Russell T, Hellewell J, Jarvis CI, van Zandvoort K, Abbott S, Ratnayake R, et al. Estimating the infection and case fatality ratio for COVID-19 using age-adjusted data from the outbreak on the Diamond Princess cruise ship, March 2020. Euro Surveill. 2020;25:2000256. https:// doi.org/ 10.2807/1560-7917.ES.2020.25.12.2000256

46. Fraser C, Donnelly CA, Cauchemez S, Hanage WP, Van Kerkhove MD, Hollingsworth TD, et al.; WHO Rapid Pandemic Assessment Collaboration. Pandemic potential of a strain of influenza A (H1N1): early findings. Science. 2009;324:1557-61. https://doi.org/10.1126/ science. 1176062 
47. Gire SK, Goba A, Andersen KG, Sealfon RSG, Park DJ, Kanneh L, et al. Genomic surveillance elucidates Ebola virus origin and transmission during the 2014 outbreak. Science. 2014;345:1369-72. https:/ / doi.org/10.1126/science.1259657

48. Rambaut A, Holmes E. The early molecular epidemiology of the swine-origin A/H1N1 human influenza pandemic. PLoS Curr. 2009;1:RRN1003. https://doi.org/10.1371/currents. RRN1003

49. Drummond AJ, Ho SYW, Phillips MJ, Rambaut A. Relaxed phylogenetics and dating with confidence. PLoS Biol. 2006;4:e88. https://doi.org/10.1371/journal.pbio.0040088

50. Huang C, Wang Y, Li X, Ren L, Zhao J, Hu Y, et al. Clinical features of patients infected with 2019 novel coronavirus in Wuhan, China. Lancet. 2020;395:497-506. https://doi.org/ 10.1016/S0140-6736(20)30183-5

51. Hellewell J, Abbott S, Gimma A, Bosse NI, Jarvis CI, Russell TW, et al. Feasibility of controlling COVID-19 outbreaks by isolation of cases and contacts. Lancet Glob Health. 2020;8:e488-96. https:/ / doi.org/10.1016/ S2214-109X(20)30074-7

52. Quilty BJ, Clifford S, Flasche S, Eggo RM, CMMID nCoV Working Group 2. Effectiveness of airport screening at detecting travellers infected with novel coronavirus (2019-nCoV). Euro Surveill. 2020;25:2000080. https:// doi.org/10.2807/1560-7917.ES.2020.25.5.2000080

53. Tian H, Liu Y, Li Y, Wu C-H, Chen B, Kraemer MUG, et al. An investigation of transmission control measures during the first 50 days of the COVID-19 epidemic in China. Science. 2020;368:638-42. https://doi.org/10.1126/ science.abb6105

54. Anzai A, Kobayashi T, Linton NM, Kinoshita R, Hayashi K, Suzuki A, et al. Assessing the impact of reduced travel on exportation dynamics of novel coronavirus infection (COVID-19). J Clin Med. 2020;9:601. https:/ / doi. org/10.3390/jcm9020601

55. Kwok KO, Li KK, Chan HHH, Yi YY, Tang A, Wei WI, et al. Community responses during early phase of COVID-19 epidemic, Hong Kong. Emerg Infect Dis. 2020;26:1575-9. https://doi.org/10.3201/eid2607.200500

56. Kraemer MUG, Yang C-H, Gutierrez B, Wu C-H, Klein B, Pigott DM, et al.; Open COVID-19 Data Working Group. The effect of human mobility and control measures on the
COVID-19 epidemic in China. Science. 2020;368:493-7. https://doi.org/10.1126/science.abb4218

57. Cameron E, Nuzzo J, Bell J, Nalabandian M, O'Brien J, League A, et al. Global Health Security Index. Washington (DC): NTI and Johns Hopkins Center for Health Security; 2019 [cited 2020 Mar 1]. https:/ / www.ghsindex.org/ wp-content/uploads/2019/10/2019-Global-Health-SecurityIndex.pdf

58. Lipsitch M, Cohen T, Cooper B, Robins JM, Ma S, James L, et al. Transmission dynamics and control of severe acute respiratory syndrome. Science. 2003;300:1966-70. https:// doi.org/10.1126/science.1086616

59. Garske T, Legrand J, Donnelly CA, Ward H, Cauchemez S, Fraser C, et al. Assessing the severity of the novel influenza A/H1N1 pandemic. BMJ. 2009;339:b2840. https://doi.org /10.1136/bmj.b2840

60. Zou L, Ruan F, Huang M, Liang L, Huang H, Hong Z, et al. SARS-CoV-2 viral load in upper respiratory specimens of infected patients. N Engl J Med. 2020;382:1177-9. https://doi.org/10.1056/NEJMc2001737

61. Yu P, Zhu J, Zhang Z, Han Y. A familial cluster of infection associated with the 2019 novel coronavirus indicating possible person-to-person transmission during the incubation period. J Infect Dis. 2020;221:1757-61. https://doi.org/10.1093/infdis/jiaa077

62. Tong Z-D, Tang A, Li K-F, Li P, Wang H-L, Yi J-P, et al. Potential presymptomatic transmission of SARS-CoV-2, Zhejiang Province, China, 2020. Emerg Infect Dis. 2020;26:1052-4. https://doi.org/10.3201/eid2605.200198

63. Bai Y, Yao L, Wei T, Tian F, Jin D-Y, Chen L, et al. Presumed asymptomatic carrier transmission of COVID-19. JAMA. 2020;323:1406-7. https:/ / doi.org10.1001/jama.2020.256

64. Hu Z, Song C, Xu C, Jin G, Chen Y, Xu X, et al. Clinical characteristics of 24 asymptomatic infections with COVID-19 screened among close contacts in Nanjing, China. Sci China Life Sci. 2020;63:706-11. https://doi.org/10.1007/ s11427-020-1661-4

Address for correspondence: Katelijn A. Vandemaele, Health Emergencies Programme, World Health Organization, 20, avenue Appia, 1211 Geneva 27, Switzerland; email vandemaelek@who.int 